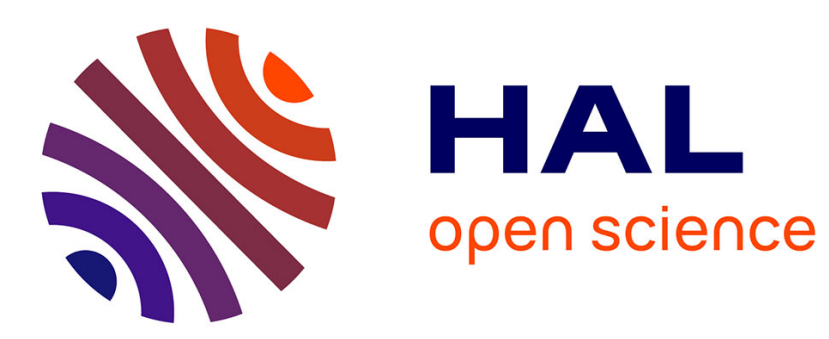

\title{
On the bulk modulus of the transition metals
}

\author{
J. Friedel, C.M. Sayers
}

\section{To cite this version:}

J. Friedel, C.M. Sayers. On the bulk modulus of the transition metals. Journal de Physique Lettres, 1978, 39 (4), pp.59-60. 10.1051/jphyslet:0197800390405900 . jpa-00231442

\section{HAL Id: jpa-00231442 https://hal.science/jpa-00231442}

Submitted on 1 Jan 1978

HAL is a multi-disciplinary open access archive for the deposit and dissemination of scientific research documents, whether they are published or not. The documents may come from teaching and research institutions in France or abroad, or from public or private research centers.
L'archive ouverte pluridisciplinaire HAL, est destinée au dépôt et à la diffusion de documents scientifiques de niveau recherche, publiés ou non, émanant des établissements d'enseignement et de recherche français ou étrangers, des laboratoires publics ou privés. 


\title{
ON THE BULK MODULUS OF THE TRANSITION METALS
}

\author{
J. FRIEDEL \\ Physique des Solides, Université de Paris-Sud, 91405 Orsay, France \\ and \\ C. M. SAYERS \\ Physics Department, Imperial College, London SW7 2BZ, U.K. \\ (Reçu le 8 novembre 1977, révisé le 6 janvier 1978, accepté le 9 janvier 1978)
}

\begin{abstract}
Résumé. - L'effet des corrélations et de l'ordre magnétique sur le module de rigidité $K$ des métaux $3 \mathrm{~d}$ est discuté à partir d'un traitement de perturbation du second ordre des corrélations.

Pour les éléments au milieu de la série, avec une faible densité d'états $n\left(E_{\mathrm{F}}\right)$ au niveau de Fermi, l'ordre ferromagnétique, s'il existe, agit de concert avec les corrélations pour réduire $K$. Les éléments $\mathrm{Fe}, \mathrm{Co}$ et $\mathrm{Ni}$ sont à la fin de la série $3 \mathrm{~d}$ et ont de fortes valeurs de $n\left(E_{\mathrm{F}}\right)$ dans l'état non magnétique. Pour ces éléments, l'effet du ferromagnétisme sur $K$ est faible et peut augmenter $K$.
\end{abstract}

\begin{abstract}
The effect of correlations and ferromagnetic order on the bulk modulus $K$ of the $3 \mathrm{~d}$ metals is discussed using a second order perturbation treatment of the correlation. For elements in the middle of the series with a low density of states $n\left(E_{\mathrm{F}}\right)$ at the Fermi level, ferromagnetic order, if possible, acts together with correlation to reduce $K$. The ferromagnetic elements $\mathrm{Fe}, \mathrm{Co}$ and $\mathrm{Ni}$ lie towards the end of the $3 \mathrm{~d}$ series and have large values of $n\left(E_{\mathrm{F}}\right)$ in the non-magnetic state. For these elements the effect of ferromagnetism on $K$ is found to be small and may act to increase $K$.
\end{abstract}

In a previous letter [1] we discussed the effect of d-electron correlation on the atomic volume and bulk modulus of the transition metals, and found that correlations give an increase in atomic volume and a decrease in bulk modulus, the effect being greatest in the middle of the $3 \mathrm{~d}$ series. The bulk modulus was evaluated at the atomic volume of the uncorrelated system, and since $\mathrm{d} K / \mathrm{d} R$ is strongly negative in the transition metals, this underestimates the decrease in $K$ due to correlations. At the atomic volume of the correlated system, the bulk modulus is given by

$K=\frac{R^{2}}{q V}\left[A q(p-q) W_{0} \mathrm{e}^{-q R}-\frac{B q}{W_{0}} \mathrm{e}^{q R}(p+q)\right]$

the difference between this result and that of [1] having the following effect.

(i) In terms of the bandwidth in the absence of correlations, $W=W_{0} \mathrm{e}^{-q R_{0}}$, equation (1) may be written as

$$
\begin{aligned}
& K=\frac{q(p-q) R_{0}^{2}}{q V_{0}} A W \times \\
& \times\left[1-\frac{1}{(p-q) R_{0}} \frac{B}{A W^{2}}\left(1+p R_{0}+2 q R_{0}\right)\right]
\end{aligned}
$$

where

$$
\alpha \equiv \frac{R-R_{0}}{R_{0}}=\frac{1}{(p-q) R_{0}} \frac{B}{A W^{2}}
$$

is the relative change in the Wigner-Seitz radius due to electron correlations. In contrast to the previous result, which gave a relative decrease in $K$ of the same magnitude as the relative increase in the atomic volume, equation (2) predicts an anomaly in $K$ about four times that in the atomic volume, in better agreement with the relative magnitudes deduced from a comparison of figures (1) and (2) of [1].

(ii) An expansion of equation (1) to first order in the change $\delta R$ in the Wigner-Seitz radius due to the onset of long range ferromagnetic order gives

$$
\delta K\left(\mu^{2}\right)=-(1+p R) K \frac{\delta R}{R}+2 q X(z) \frac{U^{2}}{W^{2}}
$$

where, for the rectangular density of states,

$$
K \delta R=q \frac{R^{2}}{q V} \frac{W \mu^{2}}{20}\left[1-[1+0.14 z(10-z)] \frac{U^{2}}{W^{2}}\right]
$$




$$
\begin{aligned}
X(z)=q \frac{R^{2}}{q V} \frac{W \mu^{2}}{20} & {[[1+0.14 z(10-z)]-} \\
& \left.-0.09 z(10-z)\left(\frac{p+q}{p-q}\right)\right]
\end{aligned}
$$

and where $R, V$ and $W$ refer to the non-magnetic state of the correlated electron gas.

The first term in (3) acts to decrease the bulk modulus as the moment in the ferromagnetic state increases, this decrease being greatest in the absence of correlations. The second term in (3) is positive for all $z$ if $p>3 q$, but is negative in the middle of the $3 \mathrm{~d}$ series if $p<3 q$. When positive this term may significantly alter the value of $\delta K$ and to investigate this further it is necessary to use a more realistic density of states. Assuming that the cohesive and correlation energies do not depend strongly on the band structure, but that the density of states at the Fermi level is important in determining the kinetic energy increase associated with ferromagnetic order, we obtain (3) with

$$
\begin{aligned}
& K \delta R=q \frac{R^{2}}{q V} \frac{\mu^{2}}{2 n\left(E_{\mathrm{F}}\right)} \times \\
& \times {\left[1-\frac{W n\left(E_{\mathrm{F}}\right)}{10}[1+0.14 z(10-z)] \frac{U^{2}}{W^{2}}\right](4 b) } \\
& X(z)=q \frac{R^{2}}{q V} \frac{\mu^{2}}{2 n\left(E_{\mathrm{F}}\right)}\left[\frac{W n\left(E_{\mathrm{F}}\right)}{10}[1+0.14 z(10-z)]-\right. \\
&\left.\quad-0.09 z(10-z)\left(\frac{p+q}{p-q}\right)\right]
\end{aligned}
$$

where $n\left(E_{\mathrm{F}}\right)$ is the total density of states at the Fermi level of the non-magnetic system. For values of $n\left(E_{\mathrm{F}}\right)$ appropriate for the ferromagnetic $3 \mathrm{~d}$ metals $\mathrm{Fe}$, Co and $\mathrm{Ni}$ with $z=7.1,8.3$ and 9.4 respectively, this perhaps oversimplified model suggests that the net effect of long range ferromagnetic order on the bulk modulus is small and may even act to increase $K$. This is in contrast to the large decrease in $K$ found by Janak and Williams [2] for iron and nickel. It is not however inconsistent with the work of Shimizu [3] using a Kanamori $I_{\text {eff }}$ who found an increase in $K$ for $\mathrm{Fe}, \mathrm{Co}$ and $\mathrm{Ni}$ with magnetization. A similar increase in $K$ with $\mu^{2}$ has been obtained by Wohlfarth and Hausch [4] in their treatment of magnetoelasticity of weak itinerant ferromagnets. For elements in the middle of the series however the second term in equation $(5 b)$ is important, particularly if $n\left(E_{\mathrm{F}}\right)$ is small as would be expected for the BCC structure.

Although a discussion of the effect of antiferromagnetism is clearly necessary, the above suggests that while in the middle of the $3 \mathrm{~d}$ series long range magnetic order may act together with correlation in reducing $K$, its effect on the ferromagnetic $3 \mathrm{~d}$ metals will be small and may even act to increase $K$. The difference between this result and that of Janak and Williams [2] and the similar one of Andersen et al. [5] might stem from the small volume dependence of the Stoner parameter found by these authors using the local density approximation to the exchange and correlation potential of the free electron gas. Although $U$ and $J$ in our model may vary with volume, the principal volume dependence in our model arises from the dependence of the interatomic electron hopping probability on the occupancy of the atoms involved, and it appears necessary to go beyond the local density approximation to include this effect.

Acknowledgments. - We wish to thank Professor E. P. Wohlfarth and the referee for helpful comments. C. M. Sayers acknowledges the S.R.C. for financial support.

\section{References}

[1] Friedel, J. and Sayers, C. M., J. Physique Lett. 38 (1977) L-263.

[2] JanaK, J. F. and Williams, A. R., Phys. Rev. B 14 (1976) 4199.

[3] Shimizu, M., Paper presented at conference on transition metals, Toronto (1977).
[4] Wohlfarth, E. P., J. Phys. F. 6 (1976) L-59. Hausch, G., J. Phys. F. 7 (1977) L-127.

[5] Andersen, O. K., Madsen, J., Poulsen, U. K., Jepsen, O. and Kollar, J., Physica B-C 86-88 (1977) 249. 